Article

\title{
Emission Flux Measurement Error with a Mobile DOAS System and Application to $\mathrm{NO}_{x}$ Flux Observations
}

\author{
Fengcheng $\mathrm{Wu}^{1}{ }^{1}$, Ang Li ${ }^{1, *}$, Pinhua Xie ${ }^{1,2,3, *}$, Hao Chen ${ }^{1}$, Zhaokun Hu ${ }^{1}$, Qiong Zhang ${ }^{1}$, \\ Jianguo Liu ${ }^{1}$ and Wenqing Liu ${ }^{1}$ \\ 1 Key Laboratory of Environmental Optical and Technology, Anhui Institute of Optics and Fine Mechanics, \\ Chinese Academy of Sciences, Hefei 230031, China; fcwu@aiofm.ac.cn (F.W.); hchen@aiofm.ac.cn (H.C.); \\ zkhu@aiofm.ac.cn (Z.H.); zhangqiong@aiofm.ac.cn (Q.Z.); jgliu@aiofm.ac.cn (J.L.); wqliu@aiofm.ac.cn (W.L.) \\ 2 Center for Excellence in Regional Atmospheric Environment, Institute of Urban Environment, \\ Chinese Academy of Sciences, Xiamen 361021, China \\ 3 School of Environmental Science and Optoeclectronic Technology, \\ University of Science and Technology of China, Hefei 230026, China \\ * Correspondence: angli@aiofm.ac.cn (A.L.); phxie@aiofm.ac.cn (P.X.); \\ Tel.: +86-551-6559-3690 (A.L.); +86-551-6559-3147 (P.X.)
}

Academic Editor: Jason K. Levy

Received: 15 December 2016; Accepted: 19 January 2017; Published: 25 January 2017

\begin{abstract}
Mobile differential optical absorption spectroscopy (mobile DOAS) is an optical remote sensing method that can rapidly measure trace gas emission flux from air pollution sources (such as power plants, industrial areas, and cities) in real time. Generally, mobile DOAS is influenced by wind, drive velocity, and other factors, especially in the usage of wind field when the emission flux in a mobile DOAS system is observed. This paper presents a detailed error analysis and NOx emission with mobile DOAS system from a power plant in Shijiazhuang city, China. Comparison of the $\mathrm{SO}_{2}$ emission flux from mobile DOAS observations with continuous emission monitoring system (CEMS) under different drive speeds and wind fields revealed that the optimal drive velocity is $30-40 \mathrm{~km} / \mathrm{h}$, and the wind field at plume height is selected when mobile DOAS observations are performed. In addition, the total errors of $\mathrm{SO}_{2}$ and $\mathrm{NO}_{2}$ emissions with mobile DOAS measurements are $32 \%$ and $30 \%$, respectively, combined with the analysis of the uncertainties of column density, wind field, and drive velocity. Furthermore, the $\mathrm{NO}_{x}$ emission of $0.15 \pm 0.06 \mathrm{~kg} / \mathrm{s}$ from the power plant is estimated, which is in good agreement with that from CEMS observations of $0.17 \pm 0.07 \mathrm{~kg} / \mathrm{s}$. This study has significantly contributed to the measurement of the mobile DOAS system on emission from air pollution sources, thus improving estimation accuracy.
\end{abstract}

Keywords: DOAS; spectrophotometer; mobile measurements; emission flux; error; $\mathrm{NO}_{\mathrm{x}}$

\section{Introduction}

China has been experiencing severe air pollution problem with the booming growth of industrialization and urbanization. The key to alleviate air pollution is the measurement, supervision, and control of its sources. The emission flux of sources is the most important and fundamental data for pollution source assessment. Currently, the primary technique for detecting emission flux is field test method, which calculates organized pollution emission based on observations of exhaust flow rate and air pollutant concentrations. However, the method cannot detect fugitive emissions, especially in area sources. In addition, the model [1,2] is also an alternative method for estimating source emission; however, it is limited to spatial scale and real-time data. 
Mobile differential optical absorption spectroscopy (mobile DOAS) [3,4] is a novel optical remote method that can estimate source emission. The technique was developed from fixed-scanning DOAS [5] observation of volcanoes and measurement of point emissions (power plants, oil refineries, etc.) and area (city, industrial areas, etc.) sources with zenith-observation DOAS system mounted on a mobile platform. Johansson et al. [3,4] and Rivera et al. [6] estimated $\mathrm{SO}_{2}, \mathrm{NO}_{2}$, and $\mathrm{HCHO}$ emissions from the industrial areas in Mexico, Beijing, and Tula (Mexico) with mobile DOAS from 2008 to 2009. NOx emissions in Mannheim, Ludwigshafen, and New Delhi city were observed by Ibrahim et al. [7] and Shaiganfar et al. [8] in 2010 and 2011 with mobile multi-axis differential optical absorption spectroscopy (mobile MAX-DOAS). From these studies, mobile DOAS has provided a novel and rapid method for source emission measurement. However, one disadvantage of this method is that the observation is affected by actual conditions (such as weather, wind, etc.). Previous studies [6] suggesting either near-surface wind from a ground meteorological station or wind at plume height from a model can be used to estimate emission. However, a detailed discussion on errors from different wind and drive speeds with mobile DOAS observations still lacks. In the current study, one power plant in Shijiazhuang city is selected as a typical point source to discuss the usage of the appropriate wind and drive speed for emission measurement using mobile DOAS. Furthermore, the total emission error of mobile DOAS is estimated based on error analysis for each impact factor of emission measurement.

Meanwhile, as one significant application of mobile DOAS, the $\mathrm{NO}_{x}$ emission from a power plant is estimated. $\mathrm{NO}_{x}$ is one of the most important trace gases in the atmosphere [9]. It participates in the catalytic formation of ozone $\left(\mathrm{O}_{3}\right)$ in the troposphere, while being a catalyst for $\mathrm{O}_{3}$ destruction in the stratosphere $[10,11] . \mathrm{NO}_{\mathrm{x}}$ sources include nature source and anthropogenic source. The main anthropogenic sources are fossil fuels (coal, oil, etc.) and biomass burning. This study explores the observation of $\mathrm{NO}_{x}$ emission from power plants with mobile DOAS preliminary and compares it with the CEMS result, showing a good agreement between the two results.

\section{Experiment and Principles}

\subsection{Overview of Experiment}

A power plant with stack height of $180 \mathrm{~m}$ was located at the south of Shijiazhuang city, a typical point source surrounded by farmlands. The construction of the power plant was divided into two stages: The first stage involves the construction of two coal-fired heating units with a total power of $600 \mathrm{MW}$, which are currently in operation. The second stage plans the construction of another two coal-fired heating units with total power of $700 \mathrm{MW}$, which is currently being actively promoted. The measurements were conducted from October to November 2011. The entire weather condition was dominated by clouds, and rain occasionally poured from 3 November to 5 November and from 7 November to 8 November for each measurement day, we conducted circular measurements and performed scanning measurements in the north of the power plant, considering good driving conditions for different drive speeds. The entire circle and scanning route was $12 \mathrm{~km}$ and $6 \mathrm{~km}$, respectively. We took approximately 30 and $15 \mathrm{~min}$ to complete the measurements. The measurement time was from 10:00 to 14:30. Furthermore, one wind LIDAR, MAX-DOAS, and some point instruments detected $\mathrm{NO}, \mathrm{NO}_{2}$, and $\mathrm{O}_{3}$ concentrations established away from the power plant $(1.7 \mathrm{~km})$. The setup of the measurement sites and two different driving routes are shown in Figure 1. 


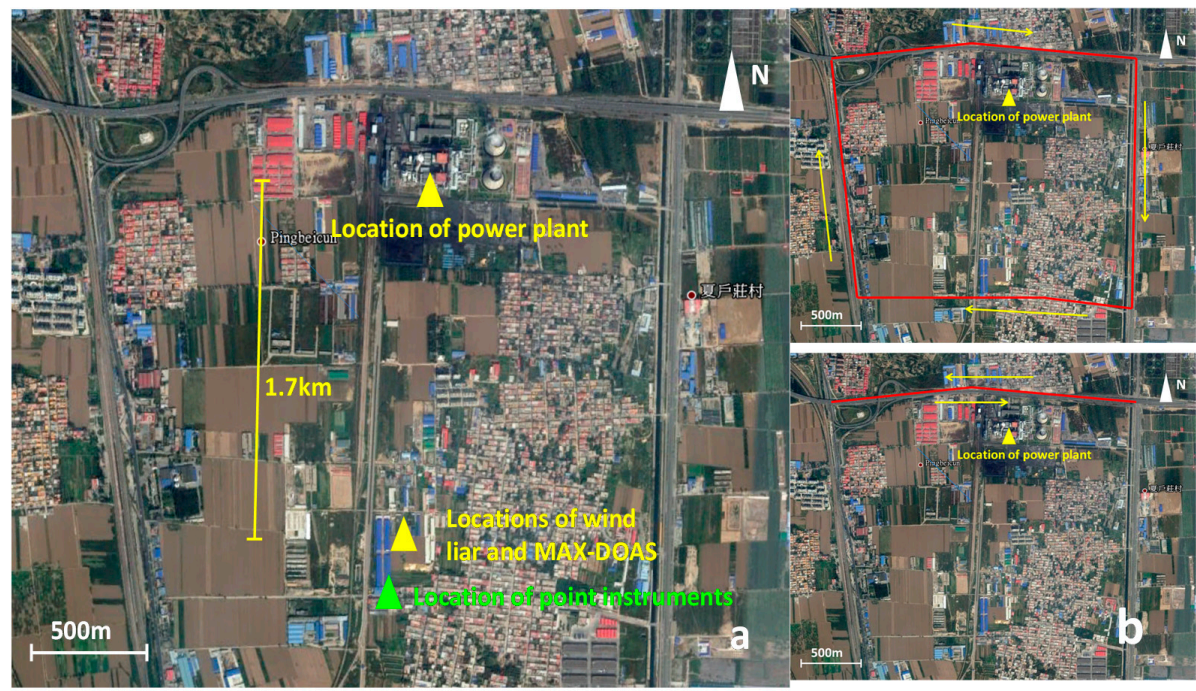

Figure 1. Setup of measurement sites (a) and two different driving routes (b). Red lines indicate the measurement routes and yellow arrows indicate the driving direction in the $(\mathbf{b})$.

\subsection{Mobile DOAS System}

The mobile DOAS system was developed at the Anhui Institute of Optics and Fine Mechanics as shown in Figure 2 [12]. The components of the instrument are spectra acquiring unit, data processing unit, and global position system (GPS) module. The spectra acquiring unit includes a zenith observation telescope and optics miniature spectrometer. The telescope collects scattered sunlight in the zenith observation and focuses into a fiber. Light collected by the telescope is transmitted to the spectrometer (HR2000+, Ocean Optics, Dunedin, FL, USA) through the fiber with spectral resolution of $0.6 \mathrm{~nm}$ and spectral wavelength range of $290-420 \mathrm{~nm}$. The spectra are then transmitted to the data processing unit to retrieve the concentration in real time through a USB data cable. GPS module is used to record geographic information and drive speed information. The system is also equipped with a miniature weather station mounted on top of the measurement van to obtain meteorological data (wind direction, wind speed, temperature, pressure, etc.). Details of the instrument and its performance are described in our previous study [13].
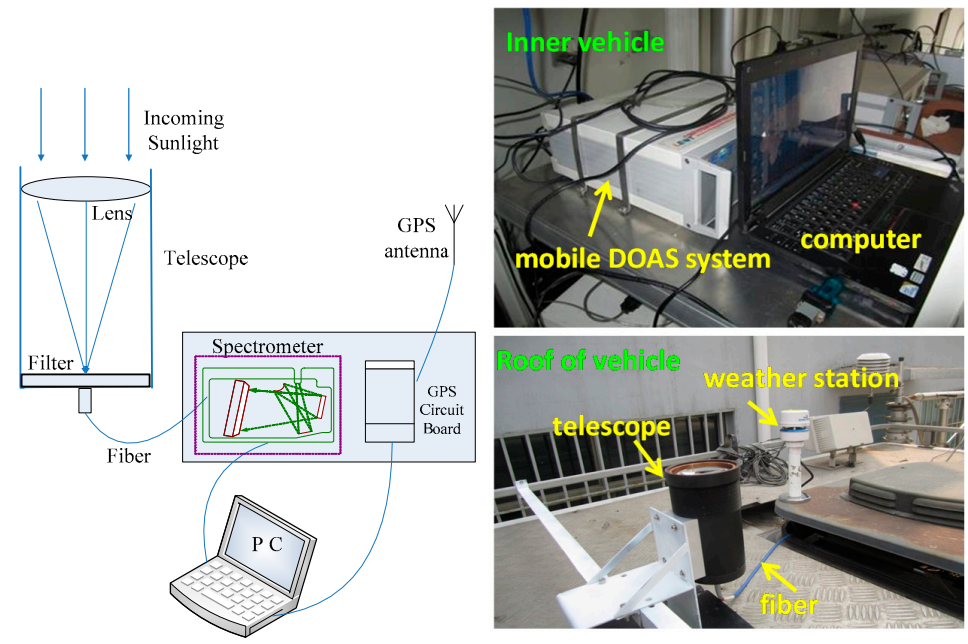

Figure 2. Mobile DOAS system. 


\subsection{Principle of Mobile DOAS}

\subsubsection{Retrieval of Vertical Column Density}

The passive DOAS technique has been employed in numerous applications that use sunlight with instruments mounted on various fixed or mobile platforms [14-19]. The evaluation procedure is described in this section in relation to our mobile observation. Details of DOAS analysis are presented in Platt and Stutz (2008) [20].

The zenith scattered sunlight $I_{0}$ is collected by the mobile DOAS as $I$ due to atmospheric extinction. $I$ and $I_{0}$ agree with the Lambert-Beer law:

$$
I=I_{0} \cdot \exp (-\sigma \cdot c \cdot L)
$$

where $\sigma$ (unit: $\mathrm{cm}^{2} /$ molec.) is the cross section of trace gas, $c$ (unit: molec. $/ \mathrm{cm}^{3}$ ) is the concentration, and $L$ (unit: $\mathrm{cm}$ ) is the length of the absorption route. The concentration of trace gas can be evaluated based on the least square fit algorithm using Equation (1). Unknown to the length of absorption route with mobile DOAS observations, the slant column density $\left(S C D\right.$, unit: molec. $\left./ \mathrm{cm}^{2}\right)$ can be retrieved using Equation (1). The $S C D$ is defined as the trace gas concentration integrated along the effective light path:

$$
S C D=\int c(l) \cdot d l=\frac{1}{\sigma}\left(\frac{I_{0}}{I}\right)
$$

The vertical column density $(V C D)$ (unit: molecules $/ \mathrm{cm}^{2}$ ) can be calculated with the $S C D$ and air mass factor ( $A M F$, non-dimensional variable) [21] as shown in Equation (3). The $A M F$ can be obtained with radiation transfer model and geometric approximation, which depends on the solar zenith angle, wavelength, and elevation angle:

$$
V C D=\frac{S C D}{A M F}
$$

\subsubsection{Estimation of Emission}

The emission of source can be detected in combination with the VCD and the measurement route, wind speed, and wind direction. For one area of interest, the emission flux is calculated using Equation (4) $[3,4,7]$ :

$$
F=\int_{A} \operatorname{div}(V C D \cdot \vec{W}) \cdot d A=\oint_{S} V C D(\vec{s}) \cdot \vec{W} \cdot \vec{n} \cdot d \vec{s}
$$

where $\vec{W}$ indicates the average wind vector, $A$ indicates the encircled area, $\vec{n}$ indicates the normal vector parallel to the Earth's surface and orthogonal to the driving direction at the position of the driving route, and $\vec{s}$ is the driving route. For mobile DOAS measurements, we can convert Equation (4) to Equation (5):

$$
F=\sum_{i} V C D\left(s_{i}\right) \cdot \vec{W} \cdot \vec{n} \cdot \Delta s_{i}=\sum_{i} V C D\left(s_{i}\right) \cdot \vec{W} \cdot \sin (\beta)\left(s_{i}\right) \cdot \Delta s_{i}
$$

where $\beta$ is the angle between the driving direction and wind direction, and $\Delta s_{i}$ is the distance between two successive spectra.

The NOx emission is estimated based on the conversion of $\mathrm{NO}_{2}$ emission with two correction factors: chemical transformation factor and lifetime correction factor:

$$
F_{N O x}=R \cdot c_{L} \cdot F_{N_{2}}=R \cdot c_{L} \cdot \sum_{i} V C D_{N_{2}}\left(s_{i}\right) \cdot \vec{W} \cdot \sin (\beta)\left(s_{i}\right) \cdot \Delta s_{i}
$$


The chemical transformation factor can be written as $\mathrm{R}=\mathrm{NO}_{\mathrm{x}} / \mathrm{NO}_{2}, \mathrm{NO}_{\mathrm{x}}=\mathrm{NO}+\mathrm{NO}_{2}$ :

$$
R=\frac{N O x}{N O_{2}}=\frac{N O+N O_{2}}{N O_{2}}=1+\frac{N O}{N O_{2}}=1+c_{\tau}
$$

$c_{\tau}=\mathrm{NO} / \mathrm{NO}_{2}$ is the Leighton ratio [11], which is generally derived from model simulations. In this study, we calculate the value from observation data of point instruments near the power plant.

$c_{L}$ in Equation (6) is the lifetime correction factor, which is derived using Equation (8):

$$
c_{L}=e^{\frac{D / W}{t}}
$$

where $D$ (unit: meters) is the mean distance from the source to the measurement site of about $2 \mathrm{~km}$ during this observation. $t$ (unit: second) indicates the NOx lifetime, which depends on photochemical reaction and meteorological condition and is difficult to determine for the specific situation of our measurements. We use an average value of $5 \mathrm{~h}$ for the NOx lifetime, which is derived from long-term satellite observations of polluted area in summer and autumn in eastern China [22].

\subsection{Data Analysis}

The VCDs of $\mathrm{SO}_{2}$ and $\mathrm{NO}_{2}$ are retrieved through the DOAS method as discussed in Section 2.3.1. During our retrieval process, a spectrum is first selected arbitrarily on the upwind path as reference spectrum to determine the concentration distribution trends along the route. The minimum concentration of $\mathrm{SO}_{2}$ and $\mathrm{NO}_{2}$ along each driving route is then chosen as the Fraunhofer spectra to re-retrieve the measurement spectra.

The wavelength range of 310 to $324 \mathrm{~nm}$ with three strong absorption peaks is selected for the $\mathrm{SO}_{2}$ fit. Absorption cross sections of $\mathrm{SO}_{2}, \mathrm{NO}_{2}, \mathrm{HCHO}, \mathrm{O}_{3}$ (Bogumil et al. [23]), and Ring are included in the fit. The Ring spectrum is generated from the measured Fraunhofer reference spectrum using the DOASIS [24] software. For the analysis of $\mathrm{NO}_{2}$, the wavelength range of 345 to $365 \mathrm{~nm}$ is selected, and the cross section of $\mathrm{O}_{4}$ at $298 \mathrm{~K}$ is also included, except for $\mathrm{NO}_{2}, \mathrm{HCHO}, \mathrm{O}_{3}$ at $293 \mathrm{~K}$ (Bogumil et al. [23]), and Ring spectrum. The wavelength calibration is performed using a highly resolved solar spectrum (Kurucz et al. [25]) convoluted by the instrument's slit function. The software of WinDOAS [26] is used to evaluate the $\mathrm{SO}_{2}$ and $\mathrm{NO}_{2} \mathrm{SCDs}$. An example for such a spectral fitting is shown in Figure 3, where the SCD is $1.92 \times 10^{17} \pm 6.56 \times 10^{15} \mathrm{molec} . / \mathrm{cm}^{2}$ and $5.76 \times 10^{16} \pm$ $1.53 \times 10^{15}$ molec. $/ \mathrm{cm}^{2}$ for $\mathrm{SO}_{2}$ and $\mathrm{NO}_{2}$, respectively. The fit uncertainties of retrieved values from these two spectra for $\mathrm{SO}_{2}$ and $\mathrm{NO}_{2}$ are about $3.41 \%$ and $2.66 \%$, respectively. For all measured spectra, the fit uncertainties are less than $15 \%$ for $\mathrm{NO}_{2}$ and $20 \%$ for $\mathrm{SO}_{2}$.
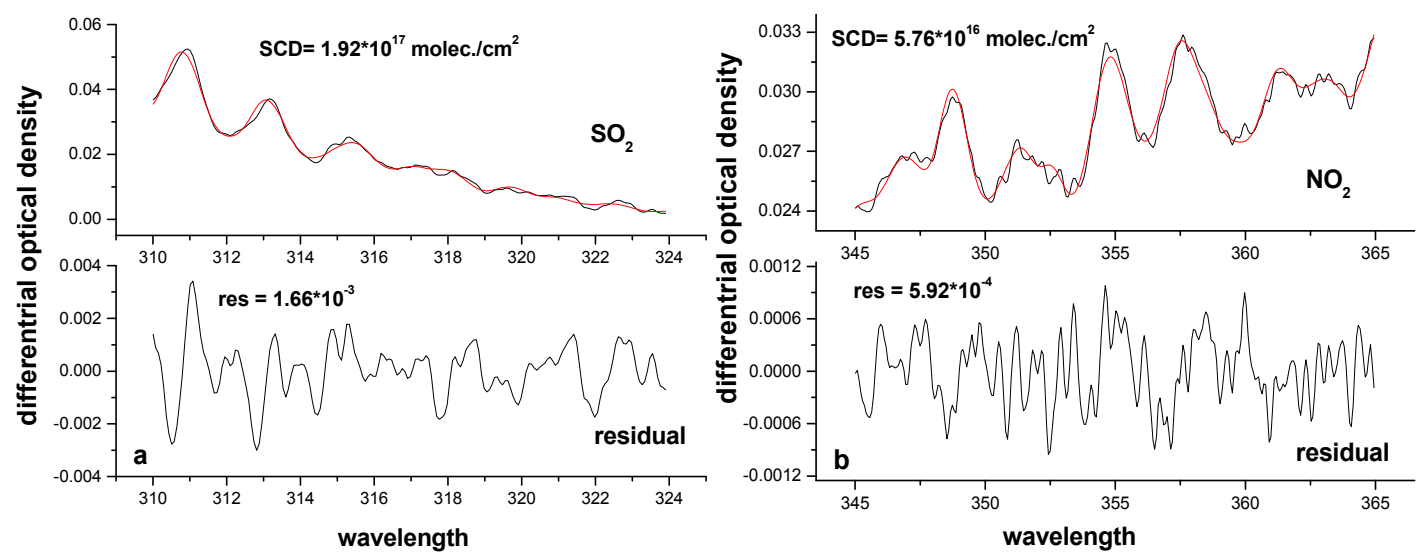

Figure 3. $\mathrm{SO}_{2}$ and $\mathrm{NO}_{2}$ fitting. The spectra are recorded at the time of 12:35:02 on 16 October 2011. (a) $\mathrm{SO}_{2}$ retrieval result, $\mathrm{SO}_{2} \mathrm{SCD}=1.92 \times 10^{17} \mathrm{molec} . / \mathrm{cm}^{2}, \mathrm{SO}_{2}$ residual $=1.66 \times 10^{-3}$; (b) $\mathrm{NO}_{2}$ retrieval result, $\mathrm{NO}_{2} \mathrm{SCD}=5.76 \times 10^{16}$ molec. $/ \mathrm{cm}^{2}, \mathrm{NO}_{2}$ residual $=5.92 \times 10^{-4}$. 
In the previous study, the VCDs of $\mathrm{SO}_{2}$ and $\mathrm{NO}_{2}$ were derived through the geometric approximation of AMF with mobile DOAS observation. According to the relationship between AMF and elevation angle $\left(A M F_{\text {trop }} \approx 1 / \sin (\alpha)\right)$, the tropospheric AMF is close to 1 due to zenith observation and measurement time at noon. As a result, the retrieved SCD is approximated to VCD. However, $A M F_{\mathrm{NO} 2}$ is larger than 1 (Figure $4 \mathrm{a}, \mathrm{b}$ ) and $A M F_{\mathrm{SO} 2}$ is approximately equal to 1 (Figure $4 \mathrm{c}, \mathrm{d}$ ), which are retrieved using a radiative transfer model McArtim [27] simulation during the measurement time. In this study, the $\mathrm{SO}_{2}$ and $\mathrm{NO}_{2}$ VCDs are calculated using the simulated AMF.
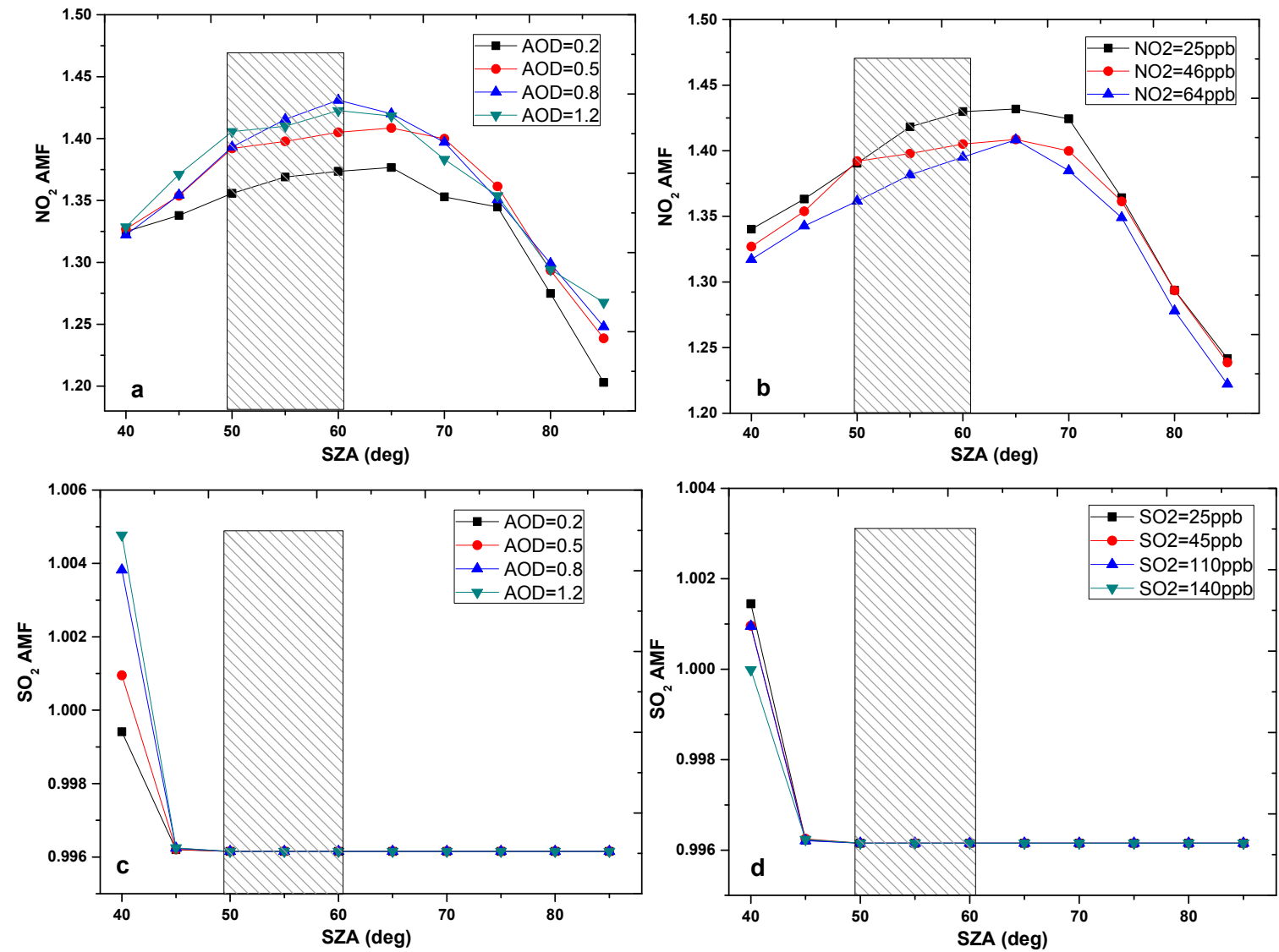

Figure 4. Simulated AMF for different aerosol and trace gas profiles. The rectangle regarding the solar zenith angle (SZA) is the time of mobile DOAS observations. (a) $\mathrm{NO}_{2}$ AMF simulation in the scenarios of different SZAs and aerosol optical density (0.2, 0.5, 0.8 and 1.2); (b) $\mathrm{NO}_{2} \mathrm{AMF}$ simulation in the scenarios of different $\mathrm{SZAs}$ and $\mathrm{NO}_{2}$ concentration $\left(25 \mathrm{ppb}, 46 \mathrm{ppb}\right.$ and $64 \mathrm{ppb}$ ) (c) $\mathrm{SO}_{2}$ AMF simulation in the scenarios of different SZAs and aerosol optical density (0.2, 0.5, 0.8 and 1.2); (d) $\mathrm{SO}_{2} \mathrm{AMF}$ simulation in the scenarios of different $\mathrm{SZAs}$ and $\mathrm{SO}_{2}$ concentration $(25 \mathrm{ppb}, 45 \mathrm{ppb}, 110 \mathrm{ppb}$ and $140 \mathrm{ppb})$.

AMF strongly depends on $\mathrm{NO}_{2}$ and aerosol profiles, which use radiative transfer model simulation. The different scenarios of aerosol, $\mathrm{SO}_{2}$, and $\mathrm{NO}_{2}$ are set to estimate the uncertainties of $\mathrm{SO}_{2}$ and $\mathrm{NO}_{2}$ AMF (Figure 4). The height of boundary layer is taken from LIDAR and ceilometer observations away from mobile DOAS $(5 \mathrm{~km})$. The concentrations of $\mathrm{SO}_{2}$ and $\mathrm{NO}_{2}$ are taken from point instruments near the power plant. The average boundary layer is about $1 \mathrm{~km}$, and aerosol optical density (AOD) ranged from 0.2 to 1.2 as observed from the LIDAR and ceilometer. We assumed that the aerosol profiles are given by constant values below the boundary layer height and exponential profiles above for the AMF simulation. The $\mathrm{NO}_{2}$ scenarios of 64,25 , and $46 \mathrm{ppb}$ and $\mathrm{SO}_{2}$ scenarios of $25,45,110$, and $140 \mathrm{ppb}$ are set based on the data from point instruments. The $\mathrm{NO}_{2}$ and $\mathrm{SO}_{2}$ profiles are given with a "box" shape, only aiming at plume observation from the power plant. 
$\mathrm{NO}_{2}$ AMF uncertainties are about $6 \%$, caused by aerosol and $\mathrm{NO}_{2}$ profiles during the measurement period (the solar zenith angle between $50^{\circ}$ and $60^{\circ}$ ) from Figure 4 . However, the $\mathrm{SO}_{2} \mathrm{AMF}$ is free of solar zenith angle, aerosol, and $\mathrm{SO}_{2}$ variations. As a result, the uncertainties of $\mathrm{SO}_{2} \mathrm{AMF}$ can be neglected compared with other errors.

\section{Analysis of Mobile DOAS Error}

\subsection{Usage of Driving Speed}

The selection of driving speed is a key factor for mobile DOAS observations, and the peak value may be lost if the driving speed is too fast. Otherwise, the conversion may be yielded for emission plume resulting in inconsistency between emission and measurement if the speed is too low. Thus, the selection of appropriate speed represented by sampling points during plume observation is important to accurately estimate emission. We have estimated the $\mathrm{SO}_{2}$ emission for different samples and compared them with those of CEMS. The optimal sampling is achieved by intercomparison of CEMS and mobile DOAS, and the optimal speed is presented combined with plume width and sampling time.

The average width of plume is calculated based on multiple scanning measurements for different sampling assuming similar weather conditions:

$$
L=\frac{\sum_{i=1}^{n} v_{i} \cdot s_{i} \cdot \Delta t_{i}}{n}
$$

where $n$ indicates the number of times of all scanning measurements, $v_{i}$ is the driving speed for each scanning measurement, and $s_{i}$ indicates the number of sampling for each scanning measurement. The average plume width, optimal sampling, and optimal speed are shown in Figure 5. The maximum and minimum plume width is $1.28 \pm 0.07 \mathrm{~km}$ and $0.53 \pm 0.11 \mathrm{~km}$, respectively, during the measurement period. The intercomparison of the results between CEMS and mobile DOAS and the sampling with the minimum difference, which is the optimal sampling, are shown in Figure 5. The optimal driving speed of $36.21 \pm 5.44 \mathrm{~km} / \mathrm{h}$ is calculated based on the average plume width, optimal sampling, and sampling time.

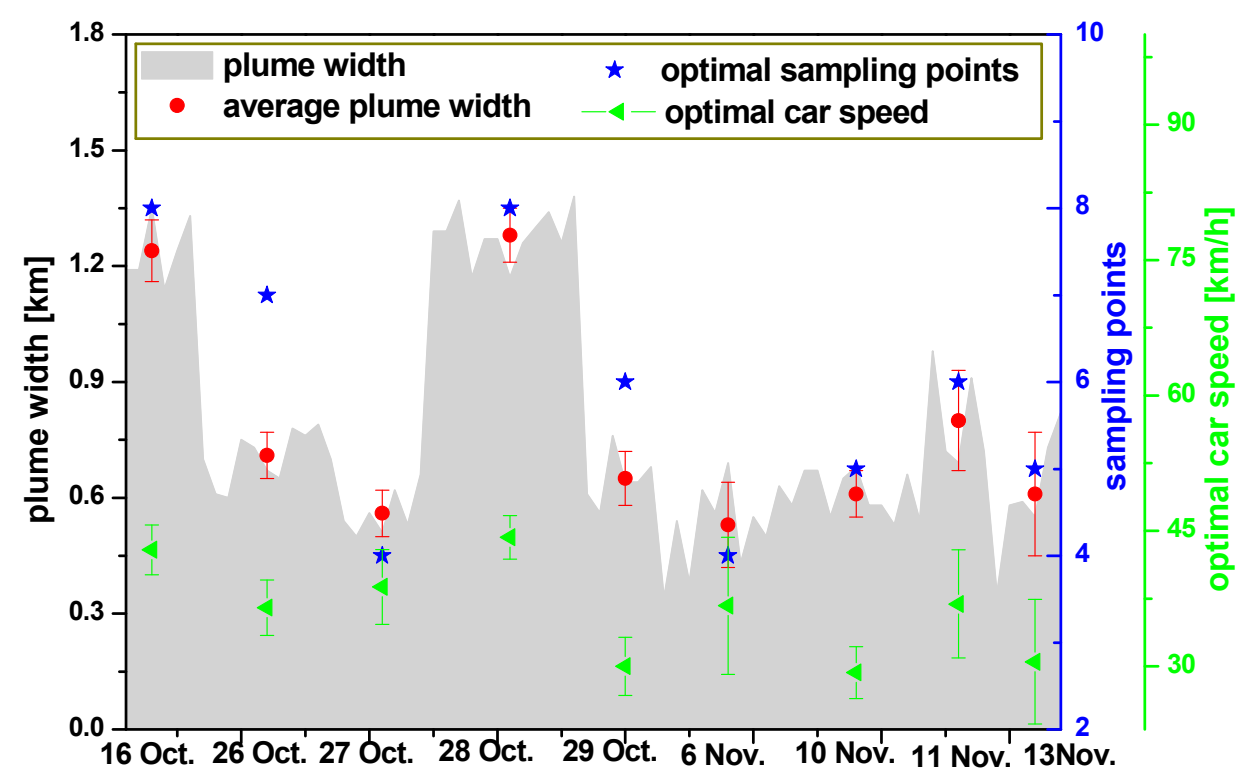

Figure 5. Plume width, average plume width, optimal sampling, and speed. 


\subsection{Usage of Wind}

Wind information is one of the largest error sources in emission estimation. The question on the usage of ground-based wind or plume-height wind has not been discussed in detail in previous studies. As shown in Figure 1, one wind LIDAR is set up near the power plant to obtain the vertical wind data, particularly the wind data at $200 \mathrm{~m}$ height. Meanwhile, we also access this data from MM5 model [28] simulation except for the LIDAR. The ground-based wind data (the altitude is about $10 \mathrm{~m}$ ) are taken from the miniature weather station mounted on the car.

The $\mathrm{SO}_{2}$ emission is estimated with ground-based wind and plume-height wind for different sampling as discussed in Section 3.1 and compared with CEMS results. Figure 6 demonstrates two examples of $\mathrm{SO}_{2}$ emission on 26 October and 10 November under different conditions.
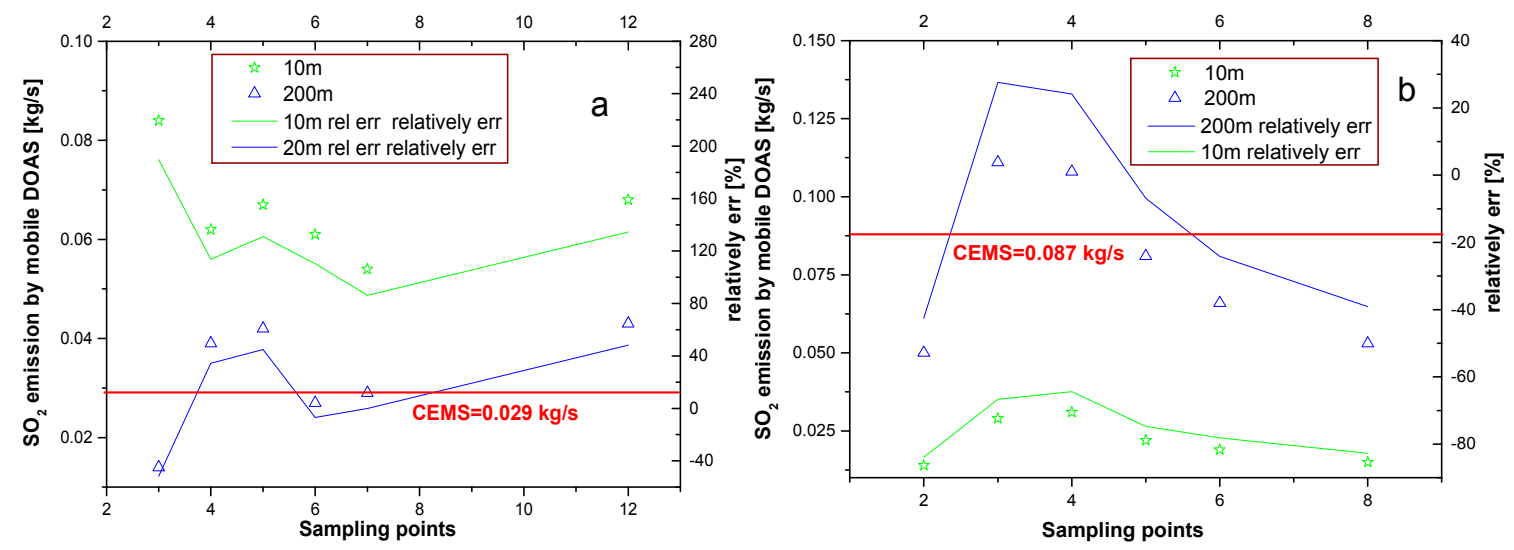

Figure 6. $\mathrm{SO}_{2}$ emission and relative deviation. (a) $\mathrm{SO}_{2}$ emission results on 26 October; (b) $\mathrm{SO}_{2}$ emission results on 10 November. The dots and lines indicate $\mathrm{SO}_{2}$ emission and relative deviation, respectively. The negative relative deviation indicates that the mobile DOAS result is lower than that of CEMS.

The emission result is closer to that of CEMS when it calculates the emission with $200 \mathrm{~m}$ height wind. In this case, the $200 \mathrm{~m}$ height is the source from the stack height of $180 \mathrm{~m}$. In addition, further results suggest the difference between mobile DOAS and CEMS, which is lower when the $200 \mathrm{~m}$ height wind and driving speed of $30-40 \mathrm{~km} / \mathrm{h}$ are used to calculate emission.

\subsection{Comparison of $\mathrm{SO}_{2}$ Emission Using Different Wind Data}

As discussed in Section 3.2, the $\mathrm{SO}_{2}$ emission estimation using mobile DOAS is more accurate when the plume height wind is adopted. The plume height wind is mainly sourced from sounding balloon, model simulation, and wind LIDAR. However, these data rather than ground-based wind data for actual measurement in general are difficult to access. To evaluate the $\mathrm{SO}_{2}$ emission error caused by wind, the ground-based wind, $200 \mathrm{~m}$ height wind from wind LIDAR or model, and $200 \mathrm{~m}$ height wind calculation from ground-based wind are used to estimate emission, and the detailed error analysis for the three types of wind data are performed in this study.

The empirical formula [29] of wind profile shows that the relationship of ground-based wind speed and different altitudes of wind speed, with altitude $z \leq 200 \mathrm{~m}$, is as follows:

$$
u=u_{0} \cdot\left(\frac{z}{z_{0}}\right)^{m}
$$

where $z_{0}$ is the altitude of the ground-based weather station $\left(z_{0}=10 \mathrm{~m}\right), u_{0}$ is the wind speed at the altitude of $z_{0}$, and $m$ is a factor that relates to atmospheric stability with $m=0.15$ [29] for "D-class" and $m=0.10$ for "C-class". This "C- or D-class" sources from six Pasquill-Turner stability class are derived from the combination of wind speed, solar radiation, and cloud cover: from 1 or A for extremely 
unstable to 6 or F for extremely stable conditions [30,31]. The atmospheric stability of "D-class" is selected for the majority of measurement time (16, 27 and 29 October and 6, 10, 11 and 13 November), except for 26 October and 28 October, which are regarded as "C-class." The related classifications are discussed in our previous study, which takes into account wind speed, solar radiation, and cloud cover [28].

Figure 7 shows the ground-based wind speed (referred to as A1), $200 \mathrm{~m}$ height wind speed source from wind LIDAR or model (referred to as B1), and $200 \mathrm{~m}$ height wind speed with calculation from ground-based wind (referred to as C1). The wind speed of A1 is lower than those of B1 and C1. Apart from the wind speed on 10 November and 13 November with the largest difference of $1.06 \mathrm{~m} / \mathrm{s}$ and $0.86 \mathrm{~m} / \mathrm{s}$, respectively, C1 agrees with B1 in most of the conditions. In addition, the wind speed trend is in good agreement for A1, B1, and C1, except for 29 October and 10 November.

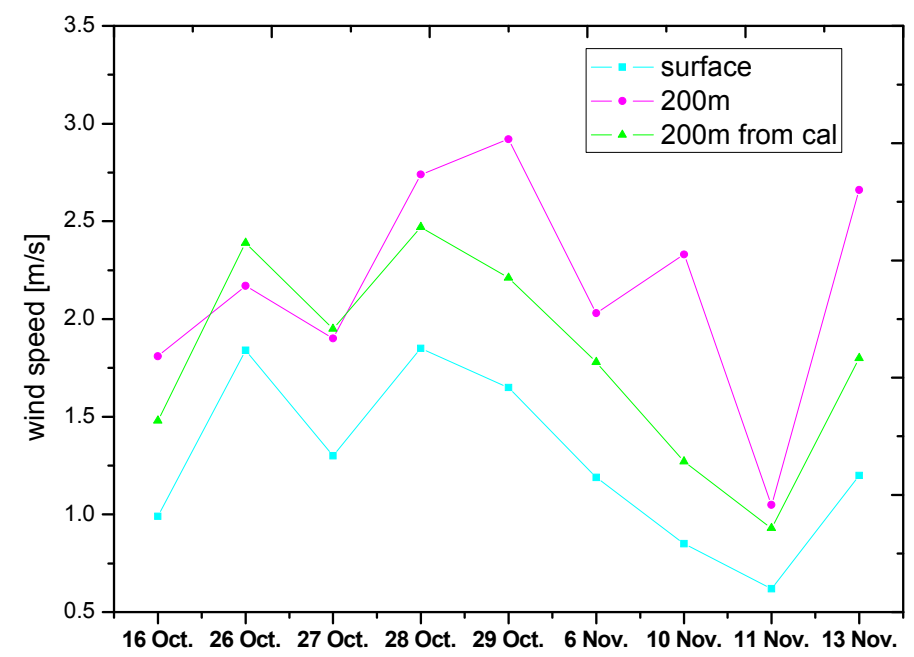

Figure 7. Three types of wind speed. Blue indicates the wind speed source from ground-based wind; pink indicates the wind speed source from $200 \mathrm{~m}$ height (LIDAR or model); and green indicates the wind speed source from $200 \mathrm{~m}$ height with calculation from ground-based wind.

Figure 8 shows that the $\mathrm{SO}_{2}$ emission estimations with $\mathrm{B} 1$ and $\mathrm{C} 1$ winds are larger than those with $\mathrm{A} 1$ as presented in Figure 6 in majority of the cases. However, the $\mathrm{SO}_{2}$ emission with $\mathrm{A} 1$ wind is larger than those with B1 and C1 on 26 October and 28 October because of the deviation of wind direction between ground-based wind and $200 \mathrm{~m}$ altitude. The ratios of emission estimation with $\mathrm{C} 1$ and $\mathrm{B} 1$ winds fluctuate around 1, whereas the maximum ratio is 1.81 and 1.88 on 26 October and 28 October, respectively. This scenario can be explained by the fact that we also consider the wind direction more than wind speed when estimating the emission. However, the empirical formula as presented in Equation (10) reveals that the wind speed at an altitude of $200 \mathrm{~m}$ and the hypothesis of wind direction for $\mathrm{C} 1$ and $\mathrm{A} 1$ agree are prerequisites when calculating the emission with $\mathrm{C} 1$ wind. In other words, the significant difference of wind direction between B1 wind and C1 wind can result in large deviation in emission estimation using B1 and C1 winds. 


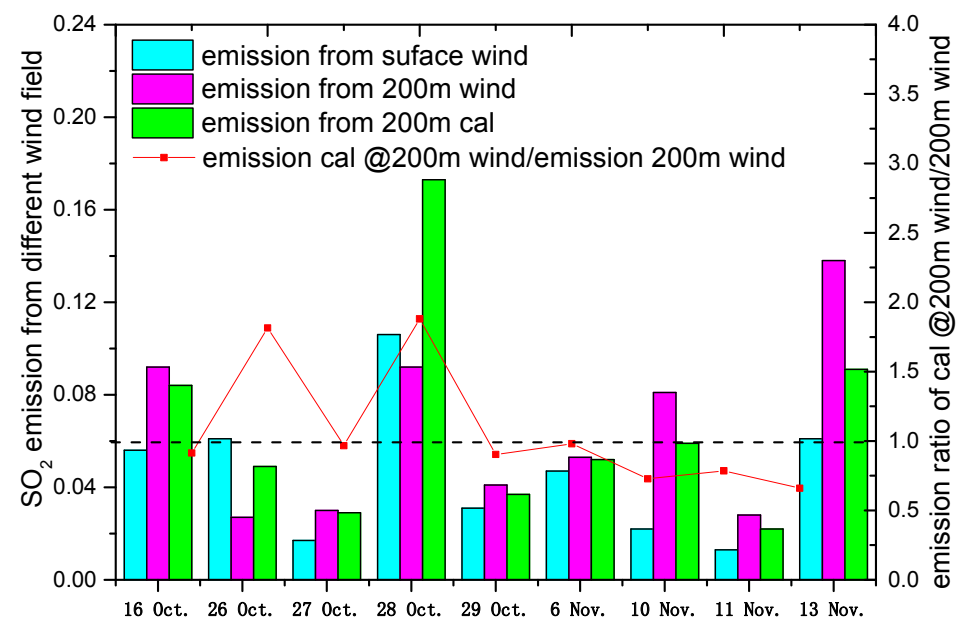

Figure 8. $\mathrm{SO}_{2}$ emission estimation with different types of wind and ratios of emission with $\mathrm{C} 1$ and B1 wind.

Table 1 lists the $\mathrm{SO}_{2}$ emission from mobile DOAS observations with three different wind and CEMS observations. It shows that the similar trends of relative deviation between CEMS and $\mathrm{SO}_{2}$ estimation with $\mathrm{B} 1$ and $\mathrm{C} 1$ winds based on mobile DOAS are presented apart from the results of 26 October and 28 October.

Table 1. Comparison of $\mathrm{SO}_{2}$ emission between mobile DOAS for three different winds and CEMS. The percentage indicates the deviation with respect to emission from CEMS. The negative values imply that CEMS is lower than those from mobile DOAS; the positive values imply otherwise.

\begin{tabular}{ccccc}
\hline & Emission from CEMS $\mathbf{~ g} / \mathbf{s}$ & Surface Wind \% & $\mathbf{2 0 0} \mathbf{~ m ~ W i n d ~ \% ~}$ & Calculation at 200 $\mathbf{~}$ Wind \% \\
\hline 16 October & 0.096 & -41.67 & -4.17 & -12.50 \\
26 October & 0.029 & 110.34 & -6.90 & 68.97 \\
27 October & 0.042 & -59.52 & -28.57 & -30.95 \\
28 October & 0.069 & 53.62 & 33.33 & 150.72 \\
29 October & 0.139 & -77.70 & -70.50 & -73.38 \\
6 November & 0.064 & -26.56 & -17.19 & -18.75 \\
10 November & 0.087 & -74.71 & -6.90 & -32.18 \\
11 November & 0.056 & -76.79 & -50.00 & -60.71 \\
13 November & 0.119 & -48.74 & -15.97 & -23.53 \\
\hline
\end{tabular}

However, although the emission estimation with B1 and C1 winds has a small difference, their ratio fluctuates around 1, which can be explained by the errors of empirical formula and the value of $\mathrm{m}$. In addition, the relatively low deviations for emission estimation with the wind of $200 \mathrm{~m}$ height further verify the discussions in Section 3.1. The result of the relatively larger deviations is caused by the fog weather on 29 October. If the plume height wind is difficult to access, then we could estimate emission with the wind calculation from ground-based wind using the empirical formula based on the mobile DOAS observations when the weather system is relatively stable and when vertical wind direction has no significant variation.

\subsection{Total Errors of Emission Flux}

According to the above analysis, the relative deviations of emission estimation are lower under a drive velocity of $30-40 \mathrm{~km} / \mathrm{h}$, and the wind field at plume height is selected when flux is calculated. However, the total errors of mobile DOAS have not been listed. This section discusses the total errors 
of emission flux based on the mobile DOAS observations. The total errors of emission flux can be calculated using Equation (11):

$$
\frac{\Delta F_{i}}{F_{i}}=\sqrt{\left(\frac{\Delta \vec{W}^{2}}{\vec{W}}\right)^{2}+\left(\frac{\Delta S C D}{S C D}\right)^{2}+\left(\frac{\Delta A M F}{A M F}\right)^{2}+\left(\frac{\Delta s}{s}\right)^{2}}
$$

From the above formula, four components are included in emission estimation errors: wind error $(\Delta \vec{W}), \operatorname{SCD}(\triangle S C D)$ error, $\operatorname{AMF}(\triangle A M F)$ error, and distance difference ( $\Delta s$, represented by drive velocity) error. The accuracy of drive speed is about $1 \%$ resulting from GPS. The drive speed variation is $1 \mathrm{~km} / \mathrm{h}$, and the flux can change by $2 \%$ to $3 \%$ from the actual calculation. Thus, the variation of $0.3-0.4 \mathrm{~km} / \mathrm{h}$ (the optimal speed is $30-40 \mathrm{~km} / \mathrm{h}$ ) for drive velocity can result in a change in approximately $1 \%$ on emission estimation. As a result, the distance difference error is $1 \%$. In addition, the SCD errors of $\mathrm{SO}_{2}$ and $\mathrm{NO}_{2}$ are low at $20 \%$ and $15 \%$, respectively, and the $\mathrm{AMF}$ error of $\mathrm{NO}_{2}$ is about $6 \%$. According to the discussions in Section 2.4, the AMF error of $\mathrm{SO}_{2}$ is negligible during the measurement periods. Furthermore, the largest error source of emission estimation is from wind field, including wind direction and wind speed errors as listed in Table 2 . The average wind error is about $25 \%$, considering the uncertainties of wind direction and wind speed. As a result, the total estimation errors of $\mathrm{SO}_{2}$ and $\mathrm{NO}_{2}$ are $32 \%$ and $30 \%$, respectively.

Table 2. Wind field uncertainty of emission estimation.

\begin{tabular}{|c|c|c|c|c|c|c|}
\hline Date & Time & $\begin{array}{c}\text { Wind } \\
\text { Direction } \\
\text { (Degree) }\end{array}$ & $\begin{array}{l}\text { Wind } \\
\text { Speed } \\
(\mathrm{m} / \mathrm{s})\end{array}$ & $\begin{array}{l}\text { Uncertainties } \\
\text { from Wind } \\
\text { Direction }\end{array}$ & $\begin{array}{c}\text { Uncertainties } \\
\text { from Wind } \\
\text { Speed }\end{array}$ & $\begin{array}{l}\text { Uncertainties } \\
\text { from Wind }\end{array}$ \\
\hline 16 October & $10: 00-12: 00$ & $274.13 \pm 2.15$ & $1.81 \pm 0.4$ & $1 \%$ & $22 \%$ & $22 \%$ \\
\hline 26 October & $12: 30-14: 00$ & $135.25 \pm 9.51$ & $2.17 \pm 0.2$ & $14 \%$ & $10 \%$ & $17 \%$ \\
\hline 27 October & $12: 00-13: 00$ & $123 \pm 6$ & $1.9 \pm 0.3$ & $19 \%$ & $14 \%$ & $24 \%$ \\
\hline 28 October & 11:40-13:00 & $183.02 \pm 10.10$ & $2.74 \pm 0.42$ & $2 \%$ & $15 \%$ & $16 \%$ \\
\hline 29 October & $13: 30-14: 10$ & $112.21 \pm 1.81$ & $2.92 \pm 0.36$ & $10 \%$ & $12 \%$ & $16 \%$ \\
\hline 6 November & 11:00-13:00 & $230.8 \pm 12$ & $2.03 \pm 0.64$ & $24 \%$ & $33 \%$ & $41 \%$ \\
\hline 10 November & $13: 00-14: 30$ & $167.67 \pm 9.46$ & $2.33 \pm 0.54$ & $3 \%$ & $24 \%$ & $25 \%$ \\
\hline 11 November & $11: 30-12: 10$ & $211.17 \pm 28.06$ & $1.05 \pm 0.29$ & $33 \%$ & $29 \%$ & $44 \%$ \\
\hline 13 November & $11: 40-12: 10$ & $192.58 \pm 7.29$ & $2.66 \pm 0.61$ & $3 \%$ & $23 \%$ & $24 \%$ \\
\hline
\end{tabular}

\subsection{Emission Estimation of NOx}

From Equation (6), the prerequisite for estimation of NOx emission is the knowledge of the ratio of $\mathrm{NO}$ and $\mathrm{NO}_{2}$, which is expected to be established for ozone-rich condition. However, the measurements are performed close to the stacks of power plants. The reaction of NO with ozone will eventually consume all available ozone, which prevents further conversion of NO into $\mathrm{NO}_{2}$. Only after additional ozone-rich air is mixed with the ozone-depleted air masses can the ratio be established. Thus, we analyze the $\mathrm{NO}, \mathrm{NO}_{2}$, and $\mathrm{O}_{3}$ concentration from point instrument observations located $1.7 \mathrm{~km}$ away from the power plant during the measurement period of this study. We calculate the ratio of $\mathrm{NO}$ and $\mathrm{NO}_{2}$ (Table 3) under an $\mathrm{O}_{3}$ concentration higher than $\mathrm{NO}$ concentration. Moreover, the $\mathrm{NO}_{\mathrm{x}}$ lifetime factor is calculated using wind speed with Equation (8). 
Table 3. $\mathrm{NO}, \mathrm{NO}_{2}$, and $\mathrm{O}_{3}$ concentration and the values of $R$ and $C_{L}$.

\begin{tabular}{cccccccc}
\hline Date & $\begin{array}{c}\mathbf{N O} \\
\mathbf{m g} / \mathbf{m}^{\mathbf{3}}\end{array}$ & $\begin{array}{c}\mathbf{N O}_{\mathbf{2}} \\
\mathbf{m g} / \mathbf{m}^{\mathbf{3}}\end{array}$ & Leighton Ratio & $\begin{array}{c}\mathbf{O}_{\mathbf{3}} \\
\mathbf{m g} / \mathbf{m}^{\mathbf{3}}\end{array}$ & $\boldsymbol{R}$ & $\boldsymbol{C}_{\boldsymbol{L}}$ & $\begin{array}{c}\text { Wind Speed } \\
\mathbf{m} / \mathbf{s}\end{array}$ \\
\hline 16 October & 0.041 & 0.072 & 0.57 & 0.042 & 1.57 & 1.06 & 1.81 \\
19 October & 0.014 & 0.041 & 0.34 & 0.024 & 1.34 & 1.04 & 3.00 \\
28 October & 0.04 & 0.116 & 0.34 & 0.048 & 1.34 & 1.06 & 2.74 \\
6 November & 0.015 & 0.044 & 0.34 & 0.048 & 1.34 & 1.07 & 2.03 \\
10 November & 0.028 & 0.063 & 0.44 & 0.028 & 1.44 & 1.05 & 2.33 \\
\hline
\end{tabular}

The NOx emission is then estimated with $R, C_{L}$, and $\mathrm{NO}_{2}$ emission flux (from mobile DOAS observation) based on Equation (6). Figure 9 shows the comparison of $\mathrm{NO}_{\mathrm{x}}$ emission between mobile DOAS and CEMS, indicating a good agreement with the average flux of $0.15 \pm 0.06 \mathrm{~kg} / \mathrm{s}$ and $0.17 \pm 0.07 \mathrm{~kg} / \mathrm{s}$ from mobile DOAS and CEMS observations, respectively.

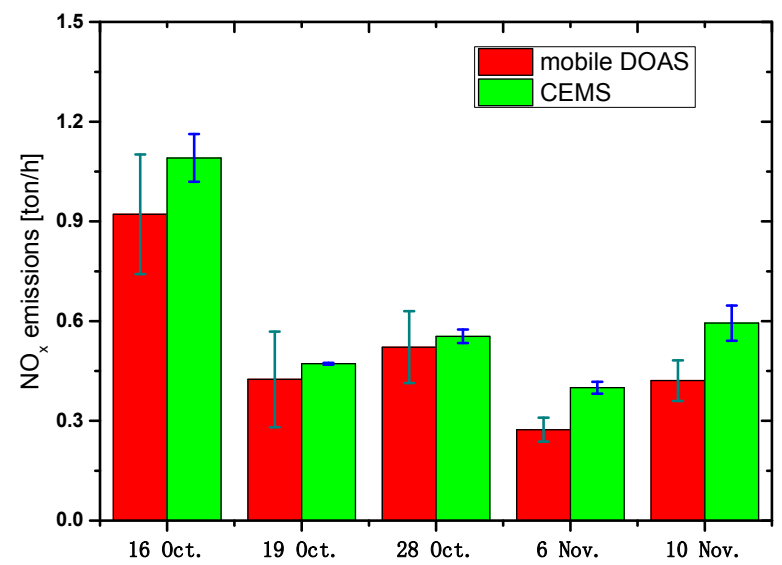

Figure 9. $\mathrm{NO}_{\mathrm{x}}$ emission flux from mobile DOAS and CEMS observations.

\section{Conclusions}

A power plant in Shijiazhuang city was selected as the experimental site to study the emission flux estimation error with a mobile DOAS system under different measurement conditions and is explored to detect $\mathrm{NO}_{\mathrm{x}}$ flux from power plant emission. This study has significantly contributed to the measurement of mobile DOAS on emission from air pollution sources, thus improving estimation accuracy.

The optimal drive velocity of $30-40 \mathrm{~km} / \mathrm{h}$ and the wind field at plume height are selected when mobile DOAS observations are made by comparing the $\mathrm{SO}_{2}$ emission flux from mobile DOAS with CEMS under different drive speeds and wind fields (ground-based and plume-height wind field). The emission flux can also be estimated with the plume-height wind speed based on empirical formula calculation when the weather system is relatively stable and vertical wind direction has no significant variation. In addition, the total error of mobile DOAS observations is estimated, which are sourced from wind field error, VCD error, and drive speed variation error. As a result, the total errors of $\mathrm{SO}_{2}$ and $\mathrm{NO}_{2}$ are $32 \%$ and $30 \%$, respectively, taking into account wind field uncertainty of $25 \%$, $\mathrm{SO}_{2}$ SCD uncertainty of $20 \%, \mathrm{NO}_{2}$ SCD uncertainty of $15 \%, \mathrm{NO}_{2}$ AMF uncertainty of $6 \%$, and drive speed uncertainty of $1 \%$. Finally, the NOx emission from the power plant is estimated with a value of $0.15 \pm 0.06 \mathrm{~kg} / \mathrm{s}$, which is in good agreement with that from CEMS observation with a value of $0.17 \pm 0.07 \mathrm{~kg} / \mathrm{s}$.

Acknowledgments: This work was made possible by the support of the National Natural Science Foundation of China (41605013, 41275038, and 41530644) and Anhui Province Natural Science Foundation of China (1508085QD71). 
Author Contributions: Pinhua Xie, Jianguo Liu and Wenqing Liu conceived, designed the experiments; Fengcheng $\mathrm{Wu}$, Ang $\mathrm{Li}$ and Hao Chen performed the experiments; Fengcheng $\mathrm{Wu}$, Zhaokun Hu and Qiong Zhang analyzed the data; Fengcheng Wu wrote the paper; Pinhua Xie and Ang Li improved the paper.

Conflicts of Interest: The authors declare no conflict of interest.

\section{References}

1. Lei, W.; de Foy, B.; Zavala, M.; Volkamer, R.; Molina, L.T. Characterizing Ozone Production in the Mexico City Metropolitan Area: A Case Study Using A Chemical Transport Model. Atmos. Chem. Phys. 2007, 7, 1347-1366. [CrossRef]

2. Zheng, J.Y.; Zhang, L.J.; Che, W.W.; Zheng, Z.Y.; Yin, S.S. A highly resolved temporal and spatial air pollutant emission inventory for the Pearl River Delta region, China and its uncertainty assessment. Atmos. Environ. 2009, 43, 5112-5122. [CrossRef]

3. Johansson, M.; Galle, B.; Yu, T.; Tang, L.; Chen, D.L.; Li, H.J.; Li, J.X.; Zhang, Y. Quantification of total emission of air pollutants from Beijing using mobile mini-DOAS. Atmos. Environ. 2008, 42, 6926-6933. [CrossRef]

4. Johansson, M.; Rivera, C.; de Foy, B.; Lei, W.; Song, J.; Zhang, Y.; Galle, B.; Molina, L. Mobile mini-DOAS measurement of the outflow of $\mathrm{NO}_{2}$ and HCHO from Mexico City. Atmos. Chem. Phys. 2009, 9, 5647-5653. [CrossRef]

5. Galle, B.; Oppenheimer, C.; Geyer, A.; McGonigle, A.J.S.; Edmonds, M.; Horrocks, L. A miniaturised ultraviolet spectrometer for remote sensing of $\mathrm{SO}_{2}$ fluxes: A new tool for volcano surveillance. J. Volcanol. Geother. Res. 2003, 119, 241-254. [CrossRef]

6. Rivera, C.; Sosa, G.; Wohrnschimmel, H.; De Foy, B.; Johansson, M.; Galle, B. Tula industrial complex (Mexico) emissions of $\mathrm{SO}_{2}$ and $\mathrm{NO}_{2}$ during the MCMA 2006 field campaign using a mobile mini-DOAS system. Atmos. Chem. Phys. 2009, 9, 6351-6361. [CrossRef]

7. Ibrahim, O.; Shaiganfar, R.; Sinreich, R.; Stein, T.; Platt, U.; Wagner, T. Car MAX-DOAS measurements around entire cities: Quantification of NOx emissions from the cities of Mannheim and Ludwigshafen (Germany). Atmos. Meas. Tech. 2010, 3, 709-721. [CrossRef]

8. Shaiganfar, R.; Beirle, S.; Sharma, M.; Chauhan, A.; Singh, R.P.; Wagner, T. Estimation of NOx emissions from Delhi using Car MAX-DOAS observations and comparison with OMI satellite data. Atmos. Chem. Phys. 2011, 11, 10871-10887. [CrossRef]

9. Elsayed, N.M. Toxicity of nitrogen dioxide: An introduction. Toxicology 1994, 89, 161-174. [CrossRef]

10. Jacob, D.J. Introduction to Atmospheric Chemistry; Princeton University Press: Princeton, NJ, USA, 1999.

11. Seinfeld, J.H.; Pandis, S.N. From Air Pollution to Climate Change. Atmospheric Chemistry and Physics, 2nd ed.; John Wiley \& Sons: New York, NY, USA, 2006.

12. Li, A.; Xie, P.H.; Liu, W.Q. Monitoring of Total Emission Volume from Pollution Sources Based on Passive Differential Optical Absorption Spectroscopy. Acta Opt. Sin. 2007, 27, 1537-1542. (In Chinese)

13. Wu, F.C.; Xie, P.H.; Li, A.; Chan, K.L.; Hartl, A.; Wang, Y.; Si, F.Q.; Zeng, Y.; Qin, M.; Xu, J.; et al. Observations of $\mathrm{SO}_{2}$ and $\mathrm{NO}_{2}$ by mobile DOAS in the Guangzhou eastern area during the Asian Games 2010. Atmos. Meas. Tech. 2013, 6, 2277-2292. [CrossRef]

14. Constantin, D.-E.; Merlaud, A.; van Roozendael, M.; Voiculescu, M.; Fayt, C.; Hendrick, F.; Pinardi, G.; Georgescu, L. Measurements of Tropospheric $\mathrm{NO}_{2}$ in Romania Using a Zenith-Sky Mobile DOAS System and Comparisons with Satellite Observations. Sensors 2013, 13, 3922-3940. [CrossRef] [PubMed]

15. Xu, J.; Xie, P.-H.; Si, F.-Q.; Li, A.; Wu, F.-C.; Wang, Y.; Liu, J.-G.; Liu, W.Q.; Hartl, A.; Lok, C.K. Observation of tropospheric $\mathrm{NO}_{2}$ by airborne multi-axis differential optical absorption spectroscopy in the Pearl River Delta region, south China. Chin. Phys. B 2014, 23, 9094210.

16. Wang, T.; Hendrick, F.; Wang, P.; Tang, G.; Clémer, K.; Yu, H.; Fayt, C.; Hermans, C.; Gielen, C.; Müller, J.F.; et al. Evaluation of tropospheric $\mathrm{SO}_{2}$ retrieved from MAX-DOAS measurements in Xianghe, China. Atmos. Chem. Phys. 2014, 14, 11149-11164. [CrossRef]

17. Strong, K.; Bailak, G.; Barton, D.; Bassford, M.; Blatherwick, R.; Brown, S.; Chartrand, D.; Davies, J.; Fogal, P.; Forsberg, E.; et al. Mantra-A balloon mission to study the odd-nitrogen budget of the stratosphere. Atmos. Ocean 2005, 43, 283-299. [CrossRef] 
18. Merlaud, A.; van Roozendael, M.; van Gent, J.; Fayt, C.; Maes, J.; Toledo-Fuentes, X.; Ronveaux, O.; de Mazière, M. DOAS measurements of $\mathrm{NO}_{2}$ from an ultralight aircraft during the Earth Challenge expedition. Atmos. Meas. Tech. 2012, 5, 2057-2068. [CrossRef]

19. Schreier, S.F.; Peters, E.; Richter, A.; Lampel, J.; Wittrock, F.; Burrows, J.P. Ship-based MAX-DOAS measurements of tropospheric $\mathrm{NO}_{2}$ and $\mathrm{SO}_{2}$ in the South China and Sulu Sea. Atmos. Environ. 2015, 102, 331-343. [CrossRef]

20. Platt, U.; Stutz, J. Differential Optical Absorption Spectroscopy: Principles and Applications; Springer: Heidelberg, Germany, 2008.

21. Honninger, G.; von Friedeburg, C.; Platt, U. Multi axis differential optical absorption spectroscopy (MAX-DOAS). Atmos. Chem. Phys. 2004, 4, 231-254. [CrossRef]

22. Lin, J.T.; McElroy, M.B.; Boersma, K.F. Constraint of anthropogenic NOx emissions in China from different sectors: A new methodology using multiple satellite retrievals. Atmos. Chem. Phys. 2010, 10, 63-78. [CrossRef]

23. Bogumil, K.; Orphal, J.; Homann, T.; Voigt, S.; Spietz, P.; Fleischmann, O.C.; Vogel, A.; Hartmann, M.; Kromminga, H.; Bovensmann, H.; et al. Measurements of molecular absorption spectra with the SCIAMACHY preflight model: Instrument characterization and reference data for atmospheric remote-sensing in the 230-2380 nm region. J. Photoch. Photobiol. A 2003, 157, 167-184. [CrossRef]

24. Kraus, S. DOASIS. A Framework Design for DOAS. Ph.D. Thesis, University of Mannheim, Shaker Verlag, Heidelberg, Germany, 2006.

25. Kurucz, R.L.; Furenlid, I.; Brault, J.; Testerman, L. Solar Flux Atlas from 296 nm to 1300 nm, National Solar Observatory Atlas No. 1; Office of University Publisher, Harvard University: Cambridge, MA, USA, 1984.

26. Van Roozendael, C.F. WinDOAS 2.1 Software User Manual; IASB/BIRA: Brussel, Belgium, 2001.

27. Tim, D.; Steffen, B.; Udo, F.; Michael, G.; Christoph, K.; Lena, K.; Ulrich, P.; Cristina, P.-R.; Janis, P.; Thomas, W.; et al. The Monte Carlo atmospheric radiative transfer model McArtim: Introduction and validation of Jacobians and 3D features. J. Quant. Spectrosc. Radiat. Transf. 2011, 112, 1119-1137.

28. Yang, J.; Li, A.; Xie, P.; Liu, W.; Wu, F.; Wang, Y.; Zeng, Y. The Application of MM5 Wind Data in Monitoring of Regional Pollution based on Passive DOAS under different Atmospheric Stability Conditions in China. In Proceedings of the 2nd International Conference on Remote Sensing, Environment and Transportation Engineering, Nanjing, China, 1-3 January 2012; Volume 5.

29. Sun, N. The Research of Atmospheric Stability and Hoist Height in Zhenjiang. Master's Thesis, Jiangsu University, Zhenjiang, China, 2007. (In Chinese)

30. Pasquill, F.; Smith, F.B. Atmospheric Diffusion, 2nd ed.; Ellis Horwood Limited: London, UK, 1983.

31. Sutherland, R.A.; Hansen, F.V.; Bach, W.D. A quantitative method for estimating Pasquill stability class from windspeed and sensible heat flux density. Bound. Layer Meteorol. 1986, 37, 357-369. [CrossRef] 